\title{
Age-related changes of the noradrenergic and acetylcholinesterase reactive nerve fibres innervating the Pigeon Bursa of Fabricius
}

\author{
E. Ciriaco*, A. Ricci**, E. Bronzetti**, C. L. Mammola*, G. Germanà ${ }^{*}$ \\ and J. A. Vega*** \\ *Istituto di Anatomia degli Animali Domestici, Facoltà di Medicina Veterinaria, \\ Università di Messina, Via S. Cecilia 30, I-98123 Messina, Italy, \\ **Dipartimento di Scienze Cardiovascolari e Respiratorie, Università “La Sapienza”, Roma, \\ Italy, and \\ ***Departamento de Morfologia y Biologia Celular, Universidad de Oviedo, Oviedo, Spain
}

Summary. Age-dependent changes in the innervation of the pigeon (Columba livia, L.) bursa of Fabricius, from hatching to 120 days of age, were studied by fluorescencehistochemical and neurochemical methods for demonstrating noradrenergic and acetylcholinesterase (AChE)reactive nerve fibres respectively. The distribution of both nerve fibre types was largely perivascular. Furthermore, a few isolated nerve fiber profiles were observed beneath the bursal epithelium, in the interfollicular septa and in the follicular cortex. No nerve fibre profiles reaching the medulla of the lymphoid follicles were observed. In addition to nerve fibres, AChE reactive neuron-like cells were encountered within the capsule and interfollicular septa. AChE reactivity was also found in dendritic-like cells localized in the cortical and cortico-medullary border. No changes in the density of perivascular noradrenergic innervation were noticeable during the ages studied, whereas the density of AChE-reactive fibres supplying vessels reached the adult pattern at 30 days, and then remained unvaried. The density of non-perivascular nerve fiber profiles, specially the AChE reactive type, increased until 30 days, remained unchanged until 75 days and then increased with aging ( $90-120$ days). The interrelationship between the autonomic nervous system and the immune system is discussed.

Key words: Bursa of Fabricius - Innervation Acetylcholinesterase - Catecholamines - Aging - Pigeon

This work was supported by a grant of MURST (60\%) 1993

Correspondence to: E. Ciriaco

\section{Introduction}

Increasing evidence suggests a close interrelationship between the nervous and immune systems (Kordon and Bihoreau 1989; Ader et al. 1990). At the peripheral level, nerves supplying lymphoid organs may participate in the differentiation and maturation of the immune-competent cells (for a review see Felten et al. 1987b; Bellinger et al. 1989, 1993). However, the mechanisms involved in this neuroimmune connection remain to be elucidated (Ader et al. 1990).

The innervation of the mammalian primary lymphoid organs has been extensively analyzed (for ref. see Bellinger et al. 1993). Conversely, little information has been obtained on the innervation of the avian bursa of Fabricius (Pintea et al. 1967; Cordier 1969; Inue 1971; Zentel et al. 1991; Zentel and Weihe 1991). This is a unique lymphoid organ, which provides the microenvironment for B lymphocyte differentiation (Glick 1983, 1991). Furthermore, it has not been established whether or not the innervation of the bursa of Fabricius undergoes changes during the growth and involutive phases of the organ (Ciriaco et al. 1985, 1989), as reported for other mammalian primary lymphoid organs (Felten et al. 1987a; Zirbes and Novotny 1992; Bellinger et al. 1993).

In view of this, we decided to investigate the age-related changes in the innervation of the pigeon (Columba livia, L.) bursa of Fabricius, using fluorescence-histochemical and neurochemical techniques for detecting noradrenergic and acetylcholinesterase (AChE) reactive nerve fibres respectively. The chronology of the development, growth and involution periods of the pigeon bursa of Fabricius has already been reported (Ciriaco et al. 1985, 1989). 


\section{Material and methods}

Male king pigeons (Columba livia, L.), Morini strain, were used in the present study. The animals were divided into three age-groups on the basis of the postnatal developmental stage of the bursa of Fabricius: i) newborn ( $0-1$ days post hatching); ii) growing postnatal period $(7,15,30,45,60$, and 75 days post hatching; Ciriaco et al. 1985); iii) regressive period (90 and 120 days post hatching; Ciriaco et al. 1989). A total number of 27 pigeons, 3 for each day of examination, were used. Under chloral hydrate anesthesia, the animals were sacrificed by decapitation and the bursa of Fabricius removed. The organs were divided into halves, embedded in a cryoprotectant medium and quickly frozen in isopentane cooled with liquid nitrogen.

$25 \mu \mathrm{m}$ thick serial sections were cut and mounted on gelatincoated slides. For demonstration of tissue stores of catecholamines, the glyoxylic acid-induced histofluorescence method was employed (De la Torre and Surgeon 1976). Microscopic slides were viewed and photographed with a Leitz microscope equipped with an epifluorescence illumination system. For acetylcholinesterase (AChE)
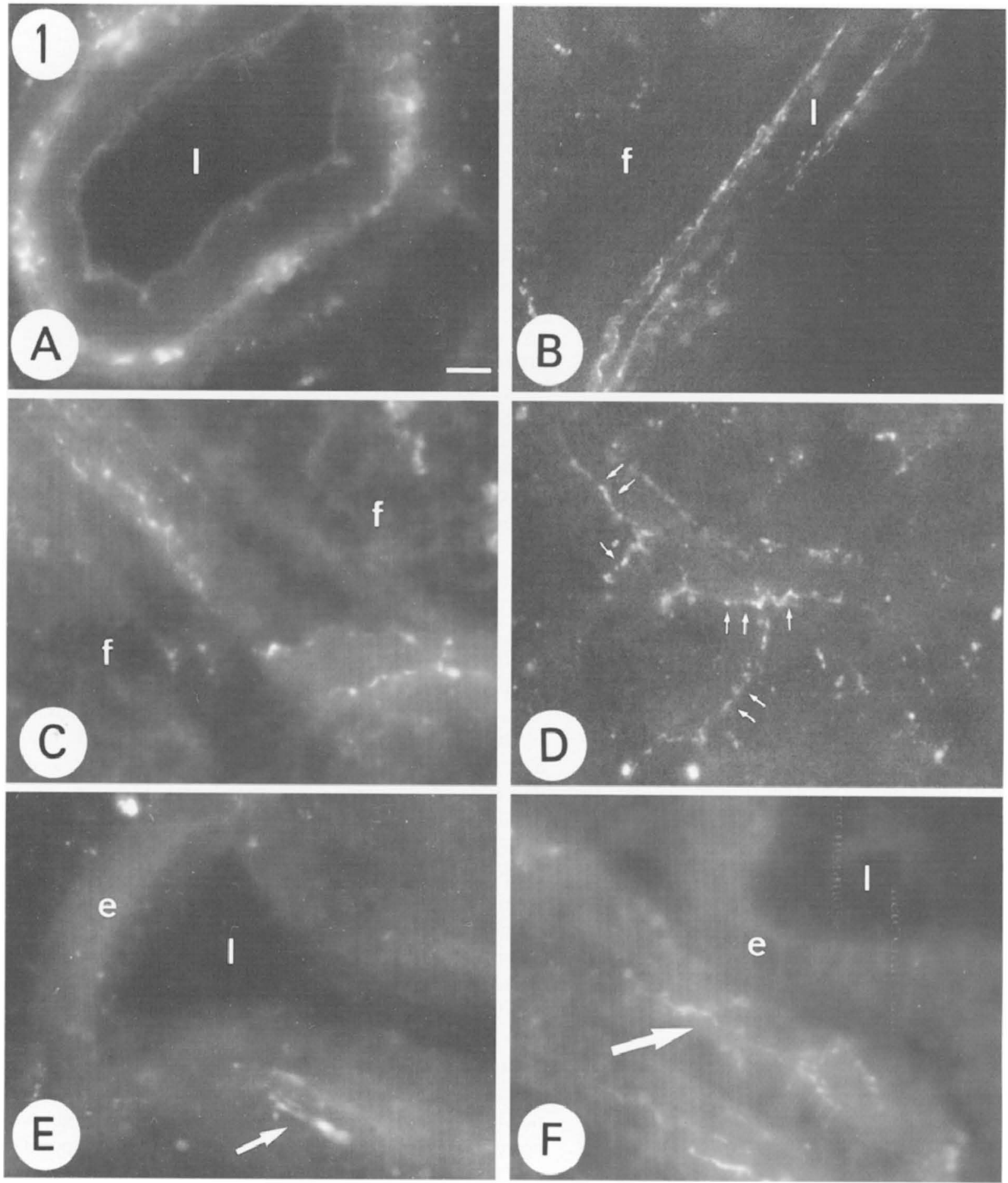

Fig. 1. Noradrenergic fibres are mainly localized forming perivascular plexuses (A, 0 days; B, 60 days), but are also found in the interfollicular connective tissue (C, 30 days; $D, 90$ days), beneath the epithelium (E, 45 days) and within the cortex of lymphoid follicles (F, 75 days). $\mathrm{e}=$ follicular epithelium; $\mathrm{f}=$ lymphoid follicles; $1=$ bursal lumen. Scale bar $=25 \mu \mathrm{m}$. 
histochemistry sections were processed according to El-Badawi and Schenk's technique (1967). Briefly, sections were incubated overnight at $4{ }^{\circ} \mathrm{C}$ in a solution containing acetyltiocholine iodide as a substrate, and iso-OMPA $(10 \mu \mathrm{M})$ as an inhibitor of non-specific cholinesterases.

The specificity of the histofluorescence which developed in the bursa of Fabricius with the employed technique was confirmed by comparing its pattern with that observed in untreated fresh sections. For AChE reactivity, controls were obtained by incubating sections either in a substrate-free medium, or in the absence of the non-specific cholinesterases inhibitor.

\section{Results}

\section{Noradrenergic nerve fibres}

Sections of the pigeon bursa of Fabricius exposed to glyoxylic acid developed blue-green fluorescent nerve fibres, rich in varicosities. Most of them were found distributed along the bursal arterial arbor (Figs. $1 \mathrm{~A}$ and 1B), but a small number were also observed in other locations, primarily in the interfollicular connective tissue (Fig. 1C and 1D). Moreover, we occasionally observed, in the 30 to 75 days-old animals, nerve fibre profiles beneath the bursal epithelium, in the cortex and at the cortico-medullary border of the lymphoid follicles (Figs. $1 \mathrm{E}$ and $1 \mathrm{~F}$ ). Nerve fibre profiles were found reaching the central part (medullary portion) of the lymphoid follicles in no case.

With regard to the density of noradrenergic innervation, no apparent variations were observed in the vascular innervation with aging. Conversely, age-dependent changes were seen in the density of non-vascular noradrenergic nerve fibres. In fact, there was a progressive increase from hatching to 30 days, no variation from 30 to 75 days, and an apparent regional increase during the involutive period of the organ (Figs. 1 C and 1D).

\section{Acetylcholinesterase-containing nerve fibres and cells}

The distribution of the perivascular AChE-positive nerve fibres was similar, and the density parallel to that described for noradrenergic fibres (Figs. 2A and 2B). However, the density of AChE-reactive perivascular nerve fibres in the newborn animals was apparently much lower than that of the catecholamine histofluorescent fibres at this age (data not shown).

AChE-reactive nerve fibres independent of blood vessels were observed in the capsule of the organ (Fig. 2B) and in the interfollicular septa (Fig. 2A), without apparently showing any age-dependent changes. Moreover, AChE-reactive structures were found subepithelially, in the cortex and at the cortico-medullary border of the lymphoid follicles (Figs. 2C-2F). The exact nature of these AChE-reactive structures remains elusive. Sometimes they showed a morphology compatible with that of nerve fibres, whereas in other cases they resembled dendritic cells or dendritic cell processes. The density of these reactive structures increased with age until day 75 , and remained unchanged during the involutive phase of the organ (Figs. $2 \mathrm{C}-2 \mathrm{~F}$ ). No AChEreactive cells were observed in the medullary compartment of the bursal follicles.

Finally, within the capsule and the interfollicular connective tissue, neuron-like cells displaying AChE reactivity cells were observed. They were either isolated or clustered, with monopolar or bipolar morphology, and intercalated in AChE-reactive networks (Figs. 2G-2I). Apparently no changes occurred in these cells with aging.

Results of the age-dependent changes in the density of noradrenergic and AChE-reactive nerve fibres are summarized in table 1.

\section{Discussion}

This study was undertaken to analyze the distribution and the age-related changes in the noradrenergic and AChEreactive nerve fibres supplying the pigeon bursa of Fabricius. The above findings provide evidence that aging of the bursa is accompanied by no changes in the density and pattern of the noradrenergic and AChE-reactive perivascular innervation. Conversely, the involutive stage is accompanied by an increase in the non-vascular noradrenergic fibres.

The nerve fibres supplying the bursa of Fabricius originate from heterogeneous sources, including intraganglionic bursal neurons (see Zentel and Weihe 1991). We have observed that the bursa contains a stable population of AChE-reactive neuron-like cells, which probably represent rudiments of the enteric nervous system involved in the innervation of the organ (see Zentel and Weihe 1991).

Our findings on the distribution of noradrenergic and AChE-reactive nerve fibres, independently of age, are in good agreement with studies reporting the distribution of peptide immunoreactive nerve fibres (Zentel and Weihe 1991; Zentel et al. 1991). Furthermore, both types of nerve fibres analyzed showed a similar pattern of distribution, thus suggesting co-localization of catecholamines with AChE-reactivity (for a review see Black et al. 1988; Landis 1988). However, the presence of a network formed exclusively of AChE-reactive nerve fibre profiles at the subepithelial and cortical follicular levels suggests the existence of an independent cholinergic innervation of the organ.

The second main goal of this study was to analyze the age-dependent changes in the innervation of the bursa of Fabricius. Our results suggest that the pattern of vascular innervation does not change with aging. Various studies carried out in mammals have revealed increase, no change or decrease in the vascular innervation of lymphoid organs with aging (for ref. see Bellinger et al. 1993). With regard to the non-vascular nerve fibres, there was, in general, a progressive increase in the density of innervation during the growth period, no modification in the adult state (see 

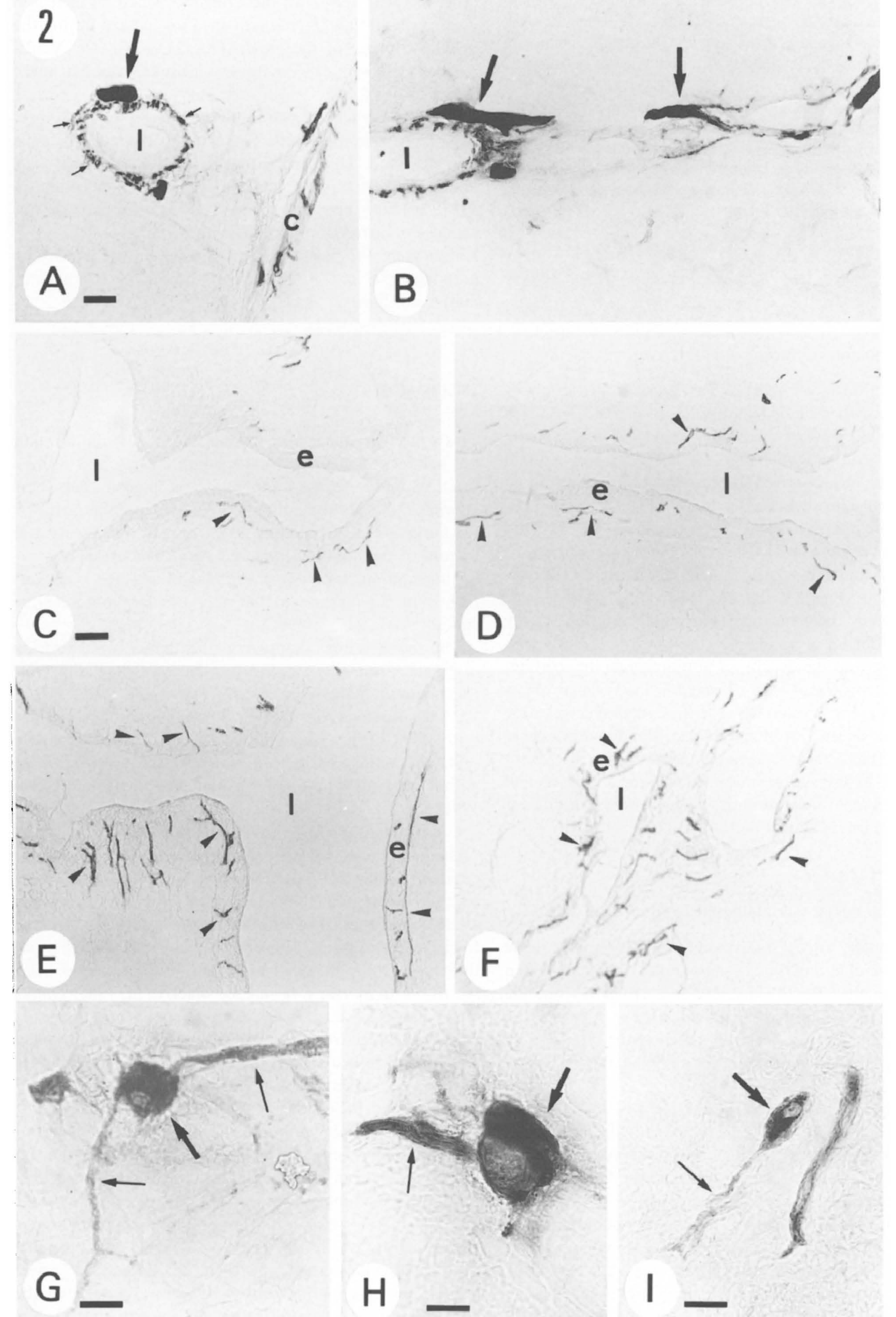

G -

H

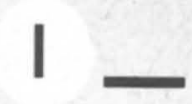


Table 1. Density of noradrenergic and AChE-reactive nerve fibres in the pigeon bursa of Fabricius at different ages $(+++:$ high; ++ : medium; +: low; - : no detectable)

\begin{tabular}{|c|c|c|c|c|c|c|c|c|c|}
\hline & \multicolumn{9}{|c|}{ Age (days) } \\
\hline & 0 & 7 & 15 & 30 & 45 & 60 & 75 & 90 & 120 \\
\hline \multicolumn{10}{|l|}{ Noradrenergic nerve fibres } \\
\hline Blood vessels & +++ & +++ & +++ & +++ & +++ & +++ & +++ & +++ & +++ \\
\hline Interfollicular septa & + & + & + & ++ & ++ & ++ & ++ & $+++^{1}$ & $+++^{1}$ \\
\hline Follicular epithelium & - & - & - & + & ++ & ++ & + & +++1 & $+++^{1}$ \\
\hline \multicolumn{10}{|l|}{ Lymphoid follicles } \\
\hline Medulla & - & - & - & - & - & - & - & - & - \\
\hline Cortico-medullary border & - & - & - & + & + & ++ & ++ & +++ & +++ \\
\hline Cortex & - & - & - & + & + & + & + & - & - \\
\hline \multicolumn{10}{|l|}{ AChE-reactive nerve fibres } \\
\hline Blood vessels & + & ++ & +++ & +++ & +++ & +++ & +++ & +++ & +++ \\
\hline Interfollicular septa & ++ & ++ & ++ & ++ & ++ & ++ & ++ & ++ & ++ \\
\hline Follicular epithelium & + & + & ++ & +++ & +++ & +++ & +++ & +++ & +++ \\
\hline \multicolumn{10}{|l|}{ Lymphoid follicles } \\
\hline Medulla & - & - & - & - & - & - & - & - & - \\
\hline Cortico-medullary border & + & + & ++ & +++ & +++ & +++ & +++ & +++ & +++ \\
\hline Cortex & + & + & + & ++ & ++ & +++ & +++ & +++ & $+t+$ \\
\hline
\end{tabular}

$\left.{ }^{1}\right)$ regional increases of nerve fibres density

Ciriaco et al. 1985) and an apparent increase in the density of noradrenergic fibres during the involutive period. Increased innervation with aging occurs in the primary lymphoid tissues of mammals, i.e. the thymus (Novotny et al. 1990; Suster and Rosai 1990; von Gaudecker 1991; Zirbes and Novotny 1992), but the functional significance of these observations has not yet been established (Bellinger et al. 1993). Whether these increase represents a relative effect, because the lymphoid tissue decreases, remains to be elucidated. However, preliminary studies (Ricci et al. unpublished) from our laboratory have demonstrated increased levels of noradrenaline in the bursa of Fabricius of old pigeons (120 days), in comparison with young or adult animals.

A striking result of the present study was the finding of AChE reactivity in cell profiles similar to that in the follicular dendritic cells. The bursal follicles contain different types of dendritic cells (see Olah et al. 1992a, b; Olah and Glick 1992), but, so far as we know, cholinergic properties have not been reported for these cells. This interesting hypothesis must be confirmed in future studies, since the dendritic cells influence the function of the immune-competent cells.

The functional significance of nerves in lymphoid organs is not clear. Data obtained in mammals demonstrate that perivascular nerves may influence the physiology of the lym- phoid organs regulating vascular blood flow (Moore et al. 1990). Moreover, it is possible that nerve fibres innervating lymphoid organs release neurotransmitters which are able to act on lymphocytes or other immune-competent cells (Payan et al. 1986; Besedowsky et al. 1989; Bulloch and Radojcic 1989). Based on the present results, a vascular control by nerve fibres in the bursa of Fabricius may be hypothesized. Moreover, since nerve fibres were also encountered in the cortical and at the cortico-medullary border, the release of neuroactive substances from nerve terminals may act directly on the cortical B lymphocytes (see Lassila 1989) or cortical dendritic cells (Glick and Olah 1987; Olah et al. 1992 a). Conversely, the absence of a direct innervation of the medullary cells suggests that the vegetative nervous system may act only indirectly on this compartment. Several studies suggest a possible role of the autonomic innervation of the immune-competent cells in the immunosenescence (see for ref. Bellinger et al. 1993). Therefore, the possibility cannot be excluded that altered noradrenergic innervation of the bursa of Fabricius with aging may be in some way related to an alteration of the immune response in senescence.

Acknowledgement. This work was supported by a grant MURST $(60 \%)$, 1993. The authors acknowledge their indebtedness to Mr. J. Hannestad for his critical review of the manuscript.

Fig. 2. AChE-reactive nerve fibres are largely perivascular (A, 30 days; B, 75 days) (arrows), but they were also identified in the interfollicular septa, beneath the epithelium, in the cortical and at the cortico-medullary border (C, 0 days; D, 15 days; E, 30 days; F, 120 days). Arrow-heads show reactive nerve-like profiles and varicose-branched structures resembling dendritic cells. AChE reactivity was also observed in the soma (large arrows) and processes (small arrows) of intra-bursal neuron-like cells (G, 7 days; H, 70 days; I, 120 days). $\mathrm{e}=$ epithelium; $1=\operatorname{vascular}(\mathrm{A}, \mathrm{B})$ or bursal $(\mathrm{C}-\mathrm{F})$ lumen. Scale bar $=25 \mu \mathrm{m}$ for $\mathrm{C}-\mathrm{F}$, and $\mathrm{H} ; 30 \mu \mathrm{m}$ for B and $\mathrm{E}$; $40 \mu \mathrm{m}$ for A and B. 


\section{References}

Ader R, Felten D, Cohen N (1990) Interactions between the brain and the immune system. Ann Rev Pharmacol Toxicol 30: $561-602$

Bellinger DL, Ackerman KD, Felten SY, Lorton D, Felten DL (1989) Noradrenergic sympathetic innervation of thymus, spleen, and lymphoid nodes: Aspects of development, aging and plasticity in neural immune interaction. In: Haden JW, Masek K, Nisticò G (eds) Interactions among CNS, Neuroendocrine and Immune Systems. Pythagora Press, Roma-Milano, pp 35-66

Bellinger DL, Felten SY, Ackerman KD, Lorton D, Madden KS, Felten DL (1993) Noradrenergic sympathetic innervation of lymphoid organs during development, aging and autoimmune disease. In: Amenta F (ed) Aging of the Autonomic Nervous System. CRC Press, Boca Raton, pp 243-283

Besedowsky HO, Del Rey A, Sorkin E (1989) Regulatory links between immune and neuroendocrine systems. Immunol Ser 45: $479-490$

Bulloch K, Radojcic T (1989) Characterization of muscarinic acetylcholine and $\beta$-adrenergic receptors of fresh and cloned immunocytes. In: Haddedd JW, Sasek K, Nistico G (eds) Interactions among CNS, Neuroendocrine and Immune Systems. Pythagora Press, Rome-Milan, pp 17-34

Black IB, Adeler JE, Le Gamma EF (1988) Neurotransmitter plasticity in the peripheral nervous system. In: Björklund A, Hökfelt T, Owman C (eds) Handbook of Chemical Neuroanatomy. Vol. 6: The Peripheral Nervous System. Elsevier Science Publisher, Amsterdam, pp 51-64

Ciriaco E, Gagliardi ME, Cicciarello R, Germanà G, Bronzetti $P$ (1985) Development of the pigeon bursa of Fabricius. A scanning and transmission electron microscope study. Anat Anz 159: $55-63$

Ciriaco E, Muglia U, Germanà G (1989) An ultrastructural study of pigeon bursa of Fabricius during involution. Anat Anz 169: $67-73$

Cordier A (1969) L'innervation de la bourse de Fabricius durant l'embryogenèse et la vie adulte. Acta Anat 73: 38-47

De la Torre JC, Surgeon JW (1976) A methodological approach to rapid and sensitive monoamine histofluorescence using modified glyoxylic acid technique: the SPG method. Histochemistry 49: $81-93$

El-Badawi A, Schenk EA (1967) Histochemical methods for separate consecutive and simultaneous demonstration of acetylcholine and norepinephrine in cryostat sections. J Histochem Cytochem 15: 580-586

Felten DL, Ackerman KD, Bellinger DL, Felten SY (1987a) Time course of depletion of noradrenergic innervation of the splenic white pulp in aged Fischer 344 rats and its relationship to declining populations of specific immune cells. Soc Neurosci Abstr 13: 1380

Felten DL, Felten SY, Bellinger DL, Carlson SL, Ackerman KD, Madden KS, Olschowska JA, Livnat (1987b) Noradrenergic sympathetic neuronal interactions with the immune system: Structure and function. Immunol Rev 100: $225-260$
Glick B (1983) Bursa of Fabricius. In: Farned DS, King JR, Parkes KC (eds) Avian Biology, Vol VII. Academic Press, New York, pp 443-449

Glick B (1991) Historical perspective: The bursa of Fabricius and its influence on B-cell development, past and present. Vet Immunol Immunopathol 30: 3-12

Glick B, Olah I (1987) Contribution of a specialized dendritic cell, the secretory cell, to the microenvironment of the bursa of Fabricius. In: Weber WT, Ewert DL (eds) Avian Immunology. Alan R Liss Inc, New York, pp 53-66

Inue K (1971) Innervation of the bursa of Fabricius in the domestic fowl. Acta Anat Nippon 46: 403-415

Kordon C, Bihoreau C (1989) Integrated communication between the nervous endocrine and immune systems. Horm Res 31: $100-104$

Landis SC (1988) Neurotransmitter plasticity in sympathetic neurons and its regulation by environmental factors in vitro and in vivo. In: Björklund A, Hökfelt T, Owman C (eds) Handbook of Chemical Neuroanatomy, Vol 6, The Peripheral Nervous System. Elsevier Science Publisher, Amsterdam, pp 64-115

Moore TM, Lami JL, Whitley GA, Ghaly A (1990) Neurovascular immunology. Vasoactive neurotransmitters and cellular immunity. Ann NY Acad Sci 594: 403-407

Novotny GEK, Sommerfeld H, Zirbes T (1990) Thymic innervation in the rat: A light and electron microscopical study. J Comp Neurol 302: $552-561$

Olah I, Glick B (1992) Follicle-associated epithelium and medullary epithelial tissue of the bursa of Fabricius are two different compartments. Anat Rec 233: 577-587

Olah I, Kendall C, Glick B (1992a) Anti-vimentin monoclonal antibody recognizes a cell with dendritic appearance in the chicken's bursa of Fabricius. Anat Rec 232: $121-125$

Olah I, Kendall C, Glick B (1992b) Differentiation of bursal secretory dendritic cells studied with anti-vimentin monoclonal antibody. Anat Rec 233: $111-120$

Payan DG, McGillis JP, Goetzl EJ (1986) Neuro-immunology. Adv Immunol 39: $299-323$

Pintea V, Constantinescu GM, Radu C (1967) Vascular and nerve supply of bursa of Fabricius in hen. Acta Vet Acad Sci Hung 17: 263-268

Suster S, Rosai J (1990) Histology of the normal thymus. Am J Surg Pathol 14: 284-303

von Gaudecker B (1991) Functional histology of the human thymus. Anat Embryol 193: 1-15

Zentel HJ, Nohr D, Albrecht R, Jeurissen SHM, Vainio O, Weihe E (1991) Peptidergic innervation of the bursa of Fabricii: interrelation with T-lymphocyte subsets. Intern J Neuroscience 59: $177-188$

Zentel HJ, Weihe E (1991) The neuro-B cell link of peptidergic innervation in the bursa Fabricii. Brain Behav Immun 5: 132-147

Zirbes T, Novotni GEK (1992) Quantification of thymic innervation in juvenile and aged rats. Acta Anat 145: 283-288

Accepted August 15, 1994 